Jurnal Ilmu Ilmu Agribisnis: Journal of Agribusiness Science, 9(3), Agustus 2021

\title{
HUBUNGAN TINGKAT KEMISKINAN DENGAN AKSES PANGAN DI KECAMATAN PARDASUKA KABUPATEN PRINGSEWU
}

(The Correlation Between Poverty Level and Food Access in Pardasuka Subdistrict Pringsewu Regency)

Nurjanah, Suriaty Situmorang, Eka Kasymir

Jurusan Agribisnis, Fakultas Pertanian, Universitas Lampung, Jl. Prof. Dr. Soemantri Brojonegoro No. 1

Bandar Lampung 35141. E-mail: suriaty.situmorang@fp.unila.ac.id

\begin{abstract}
This research aims to analyze the distribution of poor households and analyze the relation between poverty level and household food access. The method used in this research is a survey method. The location was chosen purposively with consideration that Pardasuka Subdistrict represents the highest RASKIN beneficiary area in Pringsewu Regency. The respondents are 67 households of the RASKIN beneficiary selected randomly. The research data were collected in January 2019. The distribution of poor households was analyzed descriptively and household food access was analyzed by using correlation analysis. The results showed that the distribution of poor households in Pardasuka Subdistrict consists of 47.76 percent PreProsperous, 19.40 percent Prosperous I, and 32.84 percent Prosperous II. The relation between poverty level and household food access in Pardasuka Subdistrict Pringsewu Regency is negative and significant, which means that when the food access increases, then the poverty level of the poor households decreases.
\end{abstract}

Key words: poor household, food access

\section{PENDAHULUAN}

Di Indonesia, kemiskinan telah menjadi penyakit kronis masyarakat yang tidak pernah hilang hingga saat ini. BPS (2018) mencatat jumlah penduduk miskin di Indonesia per Maret 2018 adalah 25,95 juta orang, semakin sedikit dibandingkan Bulan September 2017, yaitu 26,58 juta orang. Meski secara nasional angka kemiskinan mengalami penurunan, namun pemerintah masih memiliki pekerjaan rumah yang besar dalam menurunkan angka kemiskinan (Suhariyanto 2018).

Semakin miskin rumah tangga, maka akses pangan rumah tangga semakin rendah. Akses pangan adalah kemampuan suatu rumah tangga untuk memperoleh pangan yang cukup secara terusmenerus melalui berbagai cara, seperti produksi pangan rumah tangga, persediaan pangan rumah tangga, jual-beli, tukar-menukar/barter, pinjammeminjam, dan pemberian, atau bantuan pangan (BKP Provinsi Sumatera Utara 2008).

Hubungan tingkat kemiskinan dengan akses pangan erat kaitannya, karena keterbatasan akses untuk mendapatkan pangan, mulai dari permodalan, sarana penunjang, hingga pemasaran produk, merupakan sumber penyebab terjadinya kemiskinan.
Kabupaten Pringsewu merupakan salah satu kabupaten, yang masuk dalam sepuluh besar kabupaten termiskin di Provinsi Lampung. Tahun 2015 ke 2016, jumlah penduduk miskin mengalami peningkatan. Tahun 2015, jumlah penduduk miskin di Kabupaten Pringsewu sebanyak 11,79 persen dari total jumlah penduduk Kabupaten Pringsewu. Tahun 2016, jumlah penduduk miskin di Kabupaten Pringsewu meningkat 0,30 persen menjadi 11,82 persen meskipun peningkatan jumlah penduduk miskin tidak tinggi, namun perlu diantisipasi untuk mengurangi peningkatan jumlah kemiskinan penduduk di tahun-tahun berikutnya (BPS Provinsi Lampung 2016).

Berdasarkan data RT RW Kabupaten Pringsewu (2011), Kecamatan Pardasuka merupakan kecamatan di Kabupaten Pringsewu dengan tingkat kemiskinan yang tinggi, yaitu sebesar 3.790 kepala keluarga. Jika dilihat dari akses masyarakat untuk mendapatkan pangan, Kecamatan Pardasuka memiliki akses yang sangat rendah. Hal ini ditunjukkan oleh buruknya akses jalan, tidak adanya pasar, dan luas lahan sawah yang sempit. Berdasarkan uraian tersebut, penelitian ini bertujuan untuk menganalisi hubungan tingkat kemiskinan dengan akses pangan rumah tangga di Kecamatan Pardasuka Kabupaten Pringsewu. 


\section{METODE PENELITIAN}

Metode yang digunakan pada penelitian ini adalah metode survei. Lokasi penelitian dipilih secara sengaja dengan pertimbangan Desa Pardasuka Kecamatan Pardasuka mewakili daerah tingkat penerima bantuan RASKIN tertinggi di Kabupaten Pringsewu. Populasi penelitian sebanyak 540 rumah tangga penerima bantuan program RASKIN. Penentuan jumlah sampel menggunakan rumus perhitungan sampel Issac dan Michael dalam Sugiarto et al. (2003).

Berdasarkan perhitungan, diperoleh sampel sebanyak 67 rumah tangga. Responden dalam penelitian ini adalah kepala rumah tangga atau ibu rumah tangga dan atau anggota rumah tangga lainnya yang dianggap paling mengetahui keadaan rumah tangga, serta konsumsi rumah tangga. Penarikan sampel rumah tangga ditentukan dengan metode simple random sampling. Jenis data yang digunakan dalam penelitian ini adalah data primer dan data sekunder. Data primer diperoleh dari hasil wawancara dengan responden, menggunakan kuisioner dan daftar pertanyaan yang telah disiapkan. Pengambilan data dilakukan pada bulan Januari 2019.

Sebaran rumah tangga miskin dianalisis dengan analisis deskriptif, yaitu mendeskripsikan atau menggambarkan data yang telah terkumpul sebagaimana adanya tanpa bermaksud membuat kesimpulan yang berlaku untuk umum atau generalisasi. Rumah tangga miskin yang diteliti digolongkan dalam tiga kelompok yaitu, keluarga prasejahtera, keluarga sejahtera I dan keluarga sejahtera II. Menurut BKKBN (2011), masingmasing rumah tangga dikelompokkan berdasarkan indikator keluarga sejahtera I, keluarga sejahtera II dan keluarga sejahtera III.

Analisi hubungan tingkat kemiskinan dengan akses pangan rumah tangga dianalisis menggunakan analisis korelasi. Tahap melakukan uji analisis korelasi: (a) Mentransformasi data ordinal ke interval, karena hasil yang diperoleh dari jawaban kuesioner adalah data ordinal, maka data tersebut harus diubah menjadi data interval dengan menggunakan Metode MSI (Method of Successive Interval), agar dapat dianalisis secara statistik. Untuk mempermudah penelitian peneliti menggunakan add-in di Microsoft Excel. (b) Eksplorasi data, dilakukan dengan cara memplotkan pasangan sampel data tersebut pada diagram kartesian yang disebut dengan scatterplot atau diagram pencar. (c) Kovarian dan Korelasi.
Statistik untuk mengukur berapa banyak kedua variabel covary dalam sampel pengamatan adalah kovarian.

$$
\operatorname{Syx}=\left(\sum(x i-\ddot{x})-(y i-\tilde{y})\right) /(n-1)
$$

Keterangan:

$\begin{array}{llll}\mathrm{S} & \text { : covarian } & \ddot{\mathrm{x}} & \text { : rata-rata nilai } \mathrm{x} \\ \mathrm{xi} & \text { : nilai } \mathrm{x} & \tilde{\mathrm{y}} & \text { : rata-rata nilai } \mathrm{y} \\ \mathrm{yi} & \text { : nilai } \mathrm{y} & & \end{array}$

Menurut Hasan (2010), rumus koefisien korelasi Pearson (r), digunakan pada analisis korelasi sederhana untuk variabel interval/rasio dengan variabel interval/rasio, rumus yang digunakan adalah:

$r_{x y}=\frac{\sum X Y}{\sqrt{ }\left(\sum \mathrm{X}^{2)}\left(\sum \mathrm{Y}^{2)}\right.\right.}$

Keterangan:

rxy : koefisien korelasi

$\sum X \quad$ : jumlah skor $\mathrm{X}$

$\sum Y \quad$ : jumlah skor $\mathrm{Y}$

Untuk mempermudah peneliti perhitungan koefisien Korelasi Pearson ini menggunakan program SPSS 16.0.

\section{HASIL DAN PEMBAHASAN}

\section{Karakteristik Responden}

Rata-rata umur kepala rumah tangga responden adalah 48 tahun dan umur ibu rumah tangga 43 tahun. Rata-rata tersebut menunjukkan bahwa umur kepala dan ibu rumah tangga masih termasuk usia produktif (Mantra 2007). Jika dilihat dari tingkat pendidikan petani responden, maka tingkat pendidikan yang paling banyak dicapai oleh petani adalah tamat Sekolah Dasar sebanyak 53,73 persen.

Jumlah anggota keluarga petani di Kecamatan Pardasuka lebih banyak pada kisaran 3-4 orang sebanyak 49,25 persen. Rata-rata petani responden mempunyai pengalaman berusahatani selama 20,62 tahun sebanyak 82,09 persen. Keseluruhan petani responden tidak memiliki lahan, petani mengolah lahan milik orang lain dengan sistem bagi hasil, rata-rata luas lahan yang digarap petani responden adalah 0,01-0,50 ha sebanyak 97,01 persen. Pekerjaan utama responden semuanya adalah petani padi, dan berturut-turut sebanyak 23,88 persen, 95,52 persen, dan 32,83 persen 
responden memiliki pekerjaan sampingan sebagai pedagang, buruh, dan ojek.

Total produksi usahatani padi yang diperoleh setelah bagi hasil sebanyak $1.461 \mathrm{~kg}$ pada MT I, dan $1.256 \mathrm{~kg}$ pada MT II. Rata-rata hasil produksi yang dijual oleh petani selama dua musim tanam adalah $2.270,17 \mathrm{~kg}$ dan sebanyak $447,31 \mathrm{~kg}$ untuk dikonsumsi. Penelitian ini searah dengan Mariyani, Prasmatiwi, dan Adawiyah (2017) yang mengatakan bahwa petani padi menggunakan hasil panen untuk berbagai macam kegiatan seperti untuk konsumsi rumah tangga, dan sebagian besar hasil panen gabah untuk dijual.

Rata-rata total pendapatan petani responden Prasejahtera selama satu bulan adalah Rp2.019.661, dari total pendapatan tersebut 43 persen berasal dari pendapatan on farm, 1 persen berasal dari pendapatan off farm dan 56 persen berasal dari pendapatan non farm. Penelitian ini searah dengan penelitian Mariyani et al (2017) yang mengatakan bahwa Pendapatan petani yang berasal dari pendapatan non usahatani memiliki persentase yang lebih besar dibandingkan dengan pendapatan usahatani. Rata-rata pendapatan rumah tangga miskin di Kecamatan Pardasuka tersaji pada Tabel 1.

Pengeluaran rumah tangga meliputi pengeluaran pangan dan non pangan. Rata-rata total pengeluaran pangan rumah tangga miskin Prasejahtera di Kecamatan Pardasuka per bulan sebesar 65,87 persen dan pengeluaran untuk non pangan sebesar 34,13 persen. Hasil penelitian ini searah dengan penelitian Anggraini, Zakaria, dan Prasmatiwi (2014) bahwa pengeluaran rumah tangga untuk pangan lebih besar dari pengeluaran non pangan. Tabel pengeluaran rumah tangga tersaji pada Tabel 2 .

Tabel 1. Rata-rata pendapatan rumah tangga responden, tahun 2019

\begin{tabular}{lrrr}
\hline \multirow{2}{*}{$\begin{array}{l}\text { Sumber } \\
\text { pendapatan }\end{array}$} & \multicolumn{3}{c}{ Pendapatan RT Rp/bulan } \\
\cline { 2 - 4 } On farm & 870.924 & \multicolumn{1}{c}{ KS I } & \multicolumn{1}{c}{ KS I } \\
\hline Off farm & 14.141 & 85.004 & 1.008 .109 \\
Non farm & 1.134 .596 & 1.208 .472 & 1.052 .652 \\
\hline Jumlah & 2.019 .661 & 2.095 .546 & 2.108 .109 \\
\hline$\quad$ Sumber & $\%$ Pra & \% KS I & \% KS II \\
\hline pendapatan & & 38 & 48 \\
\hline On farm & 43 & 4 & 2 \\
Off farm & 1 & 58 & 50 \\
Non farm & 56 & 100 & 100 \\
\hline Jumlah & 100 & &
\end{tabular}

Tabel 2. Rata-rata pengeluaran rumah tangga miskin di Kecamatan Pardasuka

\begin{tabular}{|c|c|c|c|c|}
\hline \multirow{2}{*}{\multicolumn{2}{|c|}{$\begin{array}{l}\text { No Jenis pengeluaran } \\
\text { Pengeluaran pangan }\end{array}$}} & \multicolumn{3}{|c|}{ Rata-rata pengeluaran (\%) } \\
\hline & & \multirow{2}{*}{$\begin{array}{r}\text { Pra } \\
29,32\end{array}$} & \multirow{2}{*}{$\begin{array}{l}\text { KS I } \\
25,47\end{array}$} & \multirow{2}{*}{$\frac{\mathrm{KS} \text { II }}{25,38}$} \\
\hline 1 & Beras & & & \\
\hline 2 & Non beras & 0,12 & 0,15 & 0,16 \\
\hline 3 & Lauk pauk & 4,43 & 4,10 & 3,79 \\
\hline 4 & Kacang-kacangan & 2,43 & 3,39 & 3,10 \\
\hline 5 & Sayuran & 1,73 & 1,45 & 1,35 \\
\hline 6 & Buah-buahan & 1,49 & 1,52 & 1,27 \\
\hline 7 & Sumber lemak & 2,33 & 2,04 & 1,96 \\
\hline 8 & Makanan/ jajanan & 1,98 & 1,98 & 1,66 \\
\hline 9 & Minuman & 3,90 & 3,42 & 3,31 \\
\hline 10 & Bumbu-bumbu & 6,29 & 5,21 & 5,95 \\
\hline \multirow[t]{2}{*}{11} & Rokok & 11,85 & 17,63 & 11,72 \\
\hline & Total PP & 65,87 & 66,35 & 59,62 \\
\hline \multicolumn{2}{|c|}{ Pengeluaran non pangan } & Pra & KS I & KS II \\
\hline 1 & Listrik & 5,34 & 4,94 & 5,11 \\
\hline 2 & Gas & 4,70 & 4,28 & 4,30 \\
\hline 3 & $\mathrm{Bbm}$ & 7,06 & 7,27 & 8,28 \\
\hline 4 & Biaya sekolah & 0,76 & 0,51 & 0,73 \\
\hline 5 & Pakaian & 1,70 & 1,52 & 1,47 \\
\hline 6 & Kesehatan & 1,37 & 0,97 & 1,00 \\
\hline 7 & Arisan & 0,05 & 0,30 & 0,19 \\
\hline 8 & Komunikasi & 3,20 & 3,06 & 3,12 \\
\hline 9 & Keperluan mandi & 3,98 & 3,52 & 3,38 \\
\hline 10 & Kegiatan sosial & 0,44 & 0,38 & 0,38 \\
\hline 11 & Uang saku & 5,53 & 6,90 & 12,42 \\
\hline & Total PNP & 34,13 & 33,65 & 40,38 \\
\hline & btal Pengeluaran & 100,00 & 100,00 & 100,00 \\
\hline
\end{tabular}

Pengeluaran pangan petani padi terbesar yaitu dibelanjakan untuk pangan pokok beras. Rokok merupakan salah satu pengeluaran yang jumlahnya lebih besar jika dibandingkan dengan jumlah pengeluaran pangan yang lainnya yaitu sebesar 11,85 persen dari total pengeluaran rumah tangga.

Hasil penelitian ini sejalan dengan penelitian Sugesti, Abidin, dan Kalsum (2015) bahwa besarnya pengeluaran rokok melebihi besarnya pengeluaran untuk sayur sayuran, daging, telur dan susu atau pangan yang bergizi lainnya.

\section{Tingkatan Kemiskinan Petani Responden di Kecamatan Pardasuka}

Menurut BKKBN (2011), tingkatan kemiskinan dikelompokkan menjadi 5 (lima) tahapan, yaitu Tahapan Keluarga Pra Sejahtera (KPS), Tahapan Keluarga Sejahtera I (KSI), Tahapan Keluarga Sejahtera II, Tahapan Keluarga Sejahtera III, dan Tahapan Keluarga Sejahtera III Plus. Dikarenakan penelitian mengidentifikasi tingkatan kemiskinan, maka diambil tiga kelompok tingkatan kesejahteraan yang tergolong dalam kelompok miskin. 
Keluarga Pra Sejahtera (KPS) yaitu keluarga yang tidak memenuhi salah satu dari 6 (enam) indikator keluarga sejahtera I (KS I) atau indikator "kebutuhan dasar keluarga" (basic needs), dengan pengeluaran per kapita perbulan kurang dari Rp233.740,00 (BPS 2013). Keluarga Sejahtera I (KSI) adalah keluarga yang mampu memenuhi 6 (enam) indikator tahapan keluarga sejahtera I, tetapi tidak memenuhi salah satu dari 8 (delapan) indikator keluarga sejahtera II atau indikator "kebutuhan psikologis" (psychological needs) keluarga, dengan pengeluaran per kapita perbulan antara Rp233.740,00 s/d Rp280.488,00 (BPS 2013). Keluarga sejahtera II yaitu keluarga yang mampu memenuhi 6 (enam) indikator tahapan keluarga sejahtera I dan 8 (delapan) indikator keluarga sejahtera II, tetapi tidak memenuhi salah satu dari 5 (lima) indikator keluarga sejahtera III (KS III), atau indikator "kebutuhan pengembangan" (develomental needs) dari keluarga, dengan pengeluaran per kapita perbulan antara Rp280.488,00 s/d Rp350.610,00 (BPS 2013).

Berdasarkan hasil penelitian terdapat 47,76 persen kelompok petani responden keluarga prasejahtera, artinya terdapat 32 petani responden di Kecamatanan Pardasuka yang tidak dapat memenuhi salah satu dari enam indikator keluarga prasejahtera dengan tingkat pengeluaran per kapita perbulan kurang dari Rp233.740,00. Selanjutnya, sebanyak 19,40 persen petani responden dalam kelompok keluarga sejahtera I, artinya terdapat 13 keluarga petani responden yang dapat memenuhi 6 indikator keluarga prasejahtera, namun belum dapat memenuhi salah satu dari 8 indikator keluarga sejahtera I, dengan pengeluaran perkapita perbulan antara Rp233.740,00Rp280.488,00.

Presentase keluarga petani responden kelompok Sejahtera II sebanyak 32,84 atau sebanyak 22 keluarga petani responden mampu memenuhi 6 indikator keluarga prasejahtera dan mampu memenuhi 8 indikator keluarga sejahtera I, namun belum mampu memenuhi salah satu dari 5 indikatot keluarga sejahtera II, dan memiliki tingkat pengeluaran perkapita perbulan antara Rp280.488,00-Rp350.610,00.

\section{Hubungan Tingkat Kemiskinan (Prasejahtera) dengan Akses Pangan}

Berdasarkan hasil analisis Korelasi Pearson, didapatkan nilai signifikansi antara rumah tangga
Tabel 3. Hasil uji hubungan tingkat kemiskinan dengan akses pangan di Kecamatan Pardasuka, tahun 2019

\begin{tabular}{lcl}
\hline \multicolumn{1}{c}{ Keterangan } & Koefisien Korelasi & Sig \\
\hline Pra sejahtera & $-0,565^{* *}$ & 0,001 \\
Sejahtera I & $-0,753^{* *}$ & 0,003 \\
Sejahtera II & $-0,558^{* *}$ & 0,007 \\
\hline
\end{tabular}

**. Correlation is significant at the 0.01 level (2-tailed)

prasejahtera dengan akses pangan adalah 0,001. Karena nilai signifikansi $<0,05$, maka hipotesis kerja diterima, artinya terdapat hubungan antara rumah tangga prasejahtera dengan akses pangan. Selanjutnya didapatkan nilai koefisien korelasi pearson sebesar -0.565 , karena nilai koefisien korelasi pearson negatif, maka semakin tinggi keluarga prasejahtera, maka akses pangan rumah tangga di Kecamatan Pardasuka semakin rendah. Hasil uji hubungan tingkat kemiskinan dengan akses pangan di Kecamatan Pardasuka tersaji pada Tabel 3.

Hasil analisis hubungan tingkat kemiskinan (sejahtera I) dengan akses pangan didapatkan nilai signifikansi sebesar 0,003 atau kurang dari 0,05, artinya hipotesis diterima, maka ada hubungan yang signifikan antara tingkat kemiskinan keluarga petani responden sejahtera I dengan akses pangan. Nilai koefisien korelasi pearson sebesar $-0,753$, karena nilainya negatif, maka semakin tinggi tingkat rumah tangga Sejahtera I, semakin rendah akses pangan rumah tangga di Kecamatan Pardasuka.

Nilai signifikansi antara tingkat kemiskinan rumah tangga Sejahtera II dengan akses pangan adalah sebesar 0,007 atau kurang dari 0,05 artinya hipotesis diterima, sehingga ada hubungan yang signifikan antara rumah tangga sejahtera II dengan akses pangan. Nilai koefisien Korelasi Pearson sebesar $-0,558$ karena nilainya berskala negatif, artinya semakin tinggi tingkat kemiskinan rumah tangga Sejahtera II di Kecamatan Pardasuka, maka akses pangan rumah tangga di Kecamatan Padasuka semakin rendah.

Berdasarkan hasil penelitian hubungan tingkat kemiskinan dengan akses pangan di Kecamatan Pardasuka, diperoleh hasil signifikasi kurang dari 0,005 dan nilai koefisien Korelasi Person negatif. Artinya terdapat hubungan antara rumah tangga miskin dengan akses pangan. Selanjutnya, semakin tinggi tingkat rumah tangga miskin di Kecamatan Pardasuka, maka akses pangannya semakin rendah. Hasil yang diperoleh dalam penelitian ini sejalan 
dengan upaya pemerintah untuk meningkatkan kesejahteraan. Beberapa instansi yang memberikan bantuan dan melakukan upaya untuk peningkatan ketahanan pangan dan kesejahteraan petani di Kecamatan Pardasuka adalah Dinas Pertanian, Dinas Ketahanan Pangan Kabupaten Pringsewu, serta pemerintah di tingkat kecamatan dan desa.

Pemberdayaan fasilitas dan bantuan yang diberikan oleh pemerintah merupakan sarana bagi masyarakat untuk bisa berperan dalam upaya penanggulangan rawan pangan guna menurunkan tingkat kemiskinan. Dimana pemerintah berperan sebagai fasilitator dan masyarakat berperan sesuai kapasitas dan potensi yang dimiliki oleh masingmasing kelompok atau individu. Menurut Herdiana (2009), upaya mengatasi kondisi ketahanan pangan rumah tangga diantaranya dengan mengaktifkan kembali fungsi PKK, revitalisasi kelembagaan bagi petani seperti kelompok tani sebagai wadah aspirasi dan pusat memperoleh informasi, pemberian bantuan kredit dan teknologi pada petani untuk peningkatan produktivitas dan pendapatan petani, serta penyaluran RASTRA. Pernyataan tersebut sejalan dengan penelitian ini, dimana upaya-upaya yang digunakan untuk mengatasi permasalahan ketahanan pangan tersebut sama dengan upaya untuk meningkatkan akses pangan.

\section{KESIMPULAN}

Sebaran rumah tangga miskin di Kecamatan Pardasuka adalah 49,25 persen Prasejahtera, 17,91 persen Sejahtera I dan 32,84 persen Sejahtera II, dan hubungan tingkat kemiskinan dengan akses pangan di Kecamatan Pardasuka adalah negatif dan signifikan, artinya ketika tingkat kemiskinan semakin tinggi, maka akses pangan semakin rendah, atau sebaliknya semakin miskin rumah tangga, maka akses pangan semakin rendah.

\section{DAFTAR PUSTAKA}

Anggraini M, Zakaria WA, dan Prasmatiwi FE. 2014. Analisis ketahanan pangan rumah tangga petani kopi di Kabupaten Lampung Barat. Jurnal Ilmu Ilmu Agribisnis, 2 (2): 124-132. http://jurnal.fp. unila.ac.id/index.php/JIA/article/view/737. [03 November 2018].

BKP [Badan Ketahanan Pangan] Sumatera Utara. 2008. Laporan Tahunan Pangan Sumatera Utara Tahun 2008. BKP Provinsi Sumatera Utara. Medan. https://media.neliti.com/media/
publications/15241-ID-analisis-akses-pangandi-provinsi-sumatera-utara.pdf. [12 Juli 2018]

BPS [Badan Pusat Statistik] Provinsi Lampung. 2016. https://lampung.bps.go.id/dynamic table/2016/10/19/39/-dinamis-jumlahpendu duk-miskin-menurut-kabupaten-kota-20052016.html. [12 Juli 2018]

BKKBN. 2011. Batasan dan Pengertian MDK. http://aplikasi.bkkbn.go.id/ mdk/Batasan MDK.aspx. Diakses pada 12 Juli 2018

BPS [Badan Pusat Statistik]. 2013. Profil kemiskinan di Indonesia Maret 2013. http://www.bps.go.id/brs_file/kemiskinan_01j ul13.pdf. [12 Juli 2018]

BPS [Badan Pusat Statistik]. 2018. Persentase penduduk miskin Maret 2018 turun menjadi 9,82 persen. https://www.bps.go.id/pressr elease/2018/07/16/1483/persentase-penduduk -miskin-maret-2018-turun-menjadi-9-82-pers en.html\#: :text=Pada\%20bulan\%20Maret $\% 2$ 02018\%2C\%20jumlah,(10\%2C12\%20persen) [12 Juli 2018]

BPS [Badan Pusat Statistik] Provinsi Lampung. 2018. Garis Kemiskinan Provinsi Lampung Menurut Kabupaten/ Kota, 2005-2016. https://lampung.bps.go.id/linkTableDinamis/v iew/id/43. [12 Juli 2018]

Hasan I. 2010. Analisis Data Penelitian Dengan Statistik. Bumi Aksara. Jakarta.

Herdiana E. 2009. Analisis Jalur Faktor-faktor Yang Mempengaruhi Ketahanan Pangan Rumahtangga di Kabupaten Lebak, Propinsi Banten. JGP. 4 (2). https://journal.ipb.ac.id/ index.php/jgizipangan/article/view/4527. [6 Maret 2019]

Jonathan S. 2006. Metode Penelitian Kuantitatif \& Kualitatif. Graha Ilmu. Yogyakarta.

Mahasari K, Lestari DAH, Indriani Y. 2014. Kesejahteraan rumah tanggapengolah ikan teri asin di Pulau Pasaran Kecamatan Teluk Betung Barat Kota Bandar Lampung. Jurnal Ilmu Ilmu Agribisnis, 2 (2): 118-123. http://jurnal.fp.unila.ac.id /index .php/JIA/article/view/735. [6 Maret 2019]

Mantra IB. 2007. Demografi Umum. Pustaka Pelajar. Yogyakarta.

Mariyani S, Prasmatiwi FE, dan Adawiyah R. 2017. Ketersediaan pangan dan faktor-faktor yang memengaruhi ketersediaan pangan rumah tangga petani padi anggota lumbung pangan di Kecamatan Ambarawa Kabupaten Pringsewu. Jurnal Ilmu Ilmu Agribisnis, 5 (3): 304-311. http://jurnal.fp.unila.ac.id/index.php/JIA/issue /view/159/showToc. [05 Januari 2018]. 
Jurnal Ilmu Ilmu Agribisnis: Journal of Agribusiness Science, 9(3), Agustus 2021

Okpratiwi S, Haryono D, Adawiyah R. 2018. Analisis pendapatan dan tingkat kemiskinan rumah tangga petani kakao di Kecamatan Gedong Tataan Kabupaten Pesawaran. Jurnal Ilmu Ilmu Agribisnis, 6 (1): 9-16. https://jurnal.fp.unila.ac.id/index.

php/JIA/article/view/2491 [6 Maret 2019]

RTRW Kabupaten Pringsewu. 2011. Tingkat Kemiskinan Kabupaten Pringsewu. Badan Ketahanan Pangan Pringsewu. Pringsewu

Sugesti MT, Abidin Z, dan Kalsum U. 2015. Analisis pendapatan dan pengeluaran rumah tangga petani padi Desa Sukajawa, Kecamatan Bumiratu Nuban, Kabupaten
Lampung Tengah. Jurnal Ilmu Ilmu Agribisnis, 3 (3): 251-259. http://jurnal.fp.unila.ac.id/index.php/JIA/articl e/view/1049/954. [3 November 2018].

Sugiarto D, Siagian LS, Sunaryanto, dan Oetomo DS. 2003. Teknik Sampling. PT Gramedia Pustaka Utama. Jakarta

Suhariyanto. 2018. Orang Miskin di RI Berkurang 630 Ribu Jadi 25,95 Juta. Detik finance. https://finance.detik.com/berita-ekonomi-bisn is/d-4117043/maret-2018-rang-miskin-di-ri-b erkurang-630-ribu-jadi-2595-juta. 